\title{
Barcelona 2004: El fascismo postmoderno
}

\author{
Espai en Blanc ${ }^{12}$ \\ www.espaienblanc.net
}

El presente informe articula los elementos teóricos capaces de comprender de manera adecuada el régimen político que domina el territorio metropolitano de Barcelona. En este sentido intenta ofrecer un marco para el desarrollo de análisis sociales efectivamente críticos, extensible al ámbito general de la sociedad-red. Espai en Blanc ofrece su disposición a colaborar en esa tarea política, hoy más necesaria que nunca.

El informe, tal como aquí se presenta, ha sido publicado en el libro de distribución gratuita La otra cara del Forum de les Cultures S.A., de Edicions Bellaterra, 2004, en el que también se recogen textos de la Assemblea de Resistènces al Fòrum y del Colectivo Ariadna Pi (del ICA). Para pedir este libro: www.ed-bellaterra.com

${ }^{1}$ En este trabajo de Espai en Blanc han participado: Eduard Aibar, Josep Anton Ferrero, Wenceslao Galán, Marina Garcés, Santiago López Petit y Félix Vázquez

${ }^{2}$ La obviedad del mundo satura cualquier pretensión de agujerear su realidad. Pero se trata de una obviedad tramposa: afirma que vivimos en la sociedad del conocimiento y en cambio no existen ideas; inventa modelizaciones virtuales y sin embargo no hay caminos para el pensar; anima a una comunicación permanente y no obstante la comunidad resulta impensable.

Espai en Blanc quiere precisamente poner en primer plano las ideas, el pensamiento y la comunidad. Porque sabe que tenemos necesidad de vivir y de creer en lo que nos hace vivir. No es tarea fácil. No quedan vías alternativas o heterodoxas y el recurso a la cultura como lugar de encuentro no tiene valor cuando borra de las relaciones su dimensión política, mientras prosigue el avance del Estado-guerra, pavoroso y brutal, sobre el centro de nuestras vidas.

Sólo desde una actitud vanguardista podemos hacer frente a esta realidad. No aludimos ya a una vanguardia revolucionaria, que abra y sostenga un horizonte definitivamente alejado. La única vanguardia que Espai en Blanc asume es la que aspira a desaparecer, la que sin salvar a nadie nos hace a todos un poco más valientes. Actitud vanguardista significa entonces la defensa de un pensamiento crítico y experimental, que, sin recurrir a un Afuera, clandestino en la superficie de la vida, logre romper esta realidad sin límites, atrapada en las prisiones de lo obvio. Romper la realidad para liberarla y liberarnos.

Espai en Blanc surge así como un dispositivo al servicio de una práctica crítica y experimental, destinado a quienes soportan, solos, este consenso opresivo; a quienes velan sin sosiego en la oscuridad de esta luz. Espai en Blanc no quiere cambiar el mundo; sólo quiere cambiar la vida. 


\section{Índice}

PRESENTACIÓN

La marca Barcelona y la globalización. ......................................................................................... 1

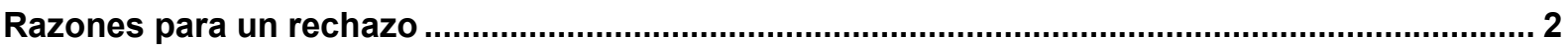

La marca Barcelona y el fascismo postmoderno ................................................................ 2

PRIMERA PARTE EL FORUM UNIVERSAL DE LAS CULTURAS: LABORATORIO DEL FASCISMO POSTMODERNO.

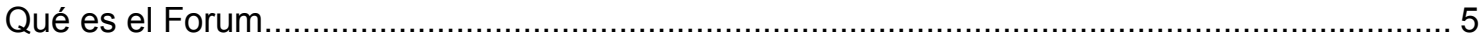

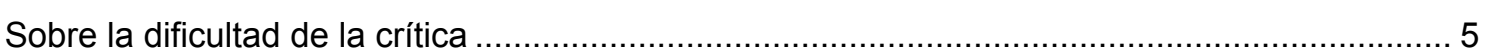

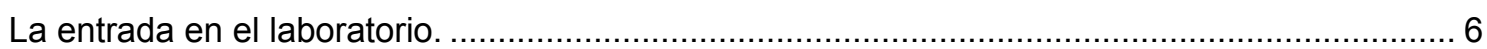

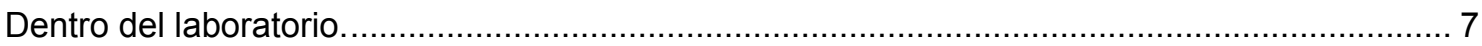

SEGUNDA PARTE ANÁLISIS DE LA MARCA BARCELONA ….............................................. 9

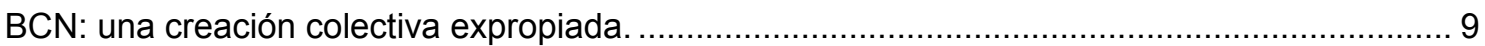

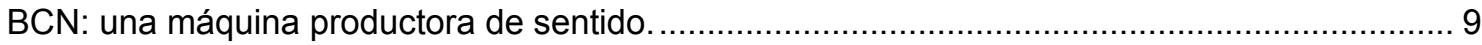

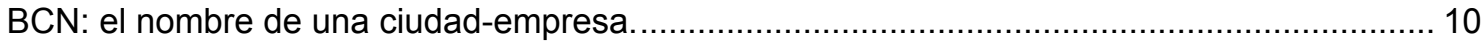

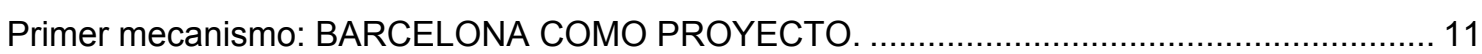

El capitalismo del conocimiento y la metrópolis....................................................... 11

La singularidad de Barcelona: un Proyecto de proyectos.......................................... 12

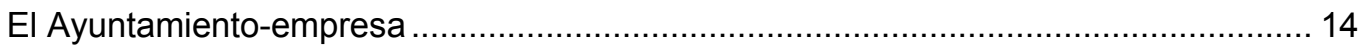

Proyecto y movilidad. El nuevo escenario social. ..................................................... 17

La movilidad sostenible como objeto y condición del Proyecto. .................................. 19

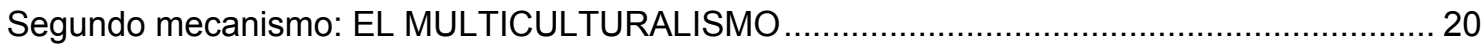

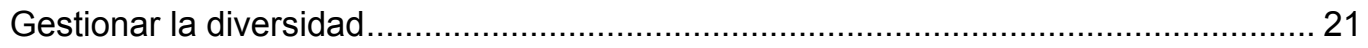

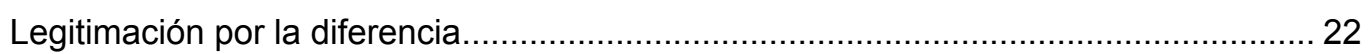

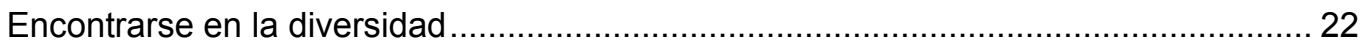

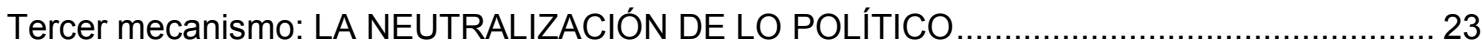

De lo político a la política: la evacuación del conflicto ................................................ 23

La política como gestión estratégica de la marca ........................................................ 24

El fascismo posmoderno y el Estado-guerra ……..................................................... 26

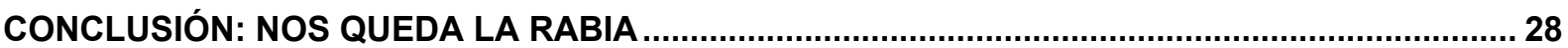

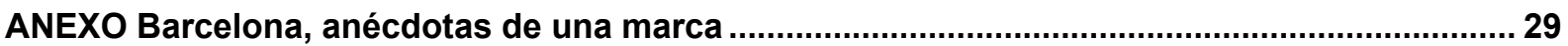




\section{PRESENTACIÓN}

\section{La marca Barcelona y la globalización.}

Barcelona no siempre ha sido una marca en el mercado de las marcas. La historia empezó en 1986, cuando Barcelona fue nominada para organizar los Juegos Olímpicos de 1992. Con el proyecto olímpico se puso en marcha una estrategia de transformación urbanística, económica y social de la ciudad, cuyo objetivo fue situarla en una posición favorable dentro de la globalización neoliberal. Es así como nuestra ciudad se transformó en la marca Barcelona.

Se nos dice que en los últimos quince años Barcelona ha pasado a ocupar un lugar destacado en el selecto grupo que lidera la jerarquía urbana europea y que supera el peso relativo de ciudades como Berlín y Roma. Todo un éxito. Pero ¿qué significa la palabra éxito aplicada aquí? ¿Para quién constituye un éxito? ¿Por qué hay que hacer de Barcelona una marca?

Mediante la marca Barcelona, la ciudad se presenta a sí misma como una de las alternativas más solventes a la dureza con la que avanzan tanto la globalización neoliberal como el Estadoguerra. La particularidad del modelo consiste en vender como posible el desarrollo económico y la cohesión social. La marca Barcelona se presenta, en concreto, como un ejemplo de ciudad abierta a las innovaciones tecnológicas pero preocupada por sus ciudadanos, como un ejemplo de metrópolis ordenada aunque dialogante, culturalmente rica y económicamente prometedora. En resumen, un modelo mundial de desarrollo armónico y feliz.

\section{Lo que nosotros afirmamos -y es lo que este Informe se propone demostrar- es que la marca Barcelona, lejos de representar esa alternativa seductora, constituye el auténtico laboratorio del fascismo postmoderno: el laboratorio de un nuevo régimen de dominación que ya no se basa en la disciplina y el consenso sino en la movilización total de las diferencias hacia un solo proyecto, hacia un solo mundo, hacia una sola realidad.}

Hablar de la marca Barcelona significa mirar la ciudad bajo la óptica de una economía ya globalizada. Lo que habitualmente llamamos "globalización" es un proceso principalmente tecnológico-financiero que se desencadenó a partir 1989, después de la caída de la URSS. No se puede olvidar, sin embargo, que esta nueva etapa del capital forma parte de la gran transformación que ha tenido lugar en los últimos treinta años y que tiene dos rasgos principales: la desarticulación de la clase trabajadora como sujeto político y la identificación entre realidad y capitalismo.

Esta identificación entre realidad y capitalismo no reduce la complejidad sino que la multiplica, ya que la nueva realidad contiene en sí todas las formas históricas de capitalismo. Indica, en cierta medida, su culminación, porque cuando la realidad coincide con el capitalismo el capital ya no tiene límite alguno ante él. Se hace inmanente a la propia realidad, con lo que el mundo se unifica en una sociedad-red sin exterior, sin afuera. Lo que era estable se disuelve y lo que se disolvía se estabiliza. En un mundo unificado, aunque en absoluto unitario, capital y poder se confunden. También lo hacen la guerra y la paz, en la nueva cruzada del Estado-guerra contra el terrorismo. Por eso la fábrica se disuelve dentro del territorio, que deviene enteramente productivo, el Estado-nacional se reconvierte 
en Estado-guerra y las ciudades pasan a ser interfaces de la nueva y reciente división del trabajo. Así pues, los actores del nuevo escenario son: el Estado-guerra, el terrorismo, las multinacionales y las ciudades. Todos compitiendo entre sí, en una implacable guerra de posiciones que deja sólo una opción: vencer o ser derrotado.

\section{Razones para un rechazo}

La marca Barcelona es el modo en que nuestra ciudad se inscribe en un mundo que, como vemos, lleva al capitalismo hasta su apogeo. La marca Barcelona compite con las otras marcas en el mercado de las marcas y tenemos que desear vivamente que esté entre las vencedoras, pues de lo contrario todos saldríamos perjudicados. La necesidad de esta guerra se presenta como algo natural. Ante la alternativa "conectarse o morir", la conversión de Barcelona en una marca entre las marcas aparece como algo indiscutible. Nosotros desconocemos si otra globalización es posible seguramente no-; lo que sí sabemos es que la marca Barcelona, la Barcelona 2004, es repugnante y que la rechazamos por cinco razones fundamentales:

1) Porque comporta demasiadas injusticias. Injusticias como la especulación desaforada y el enriquecimiento de unos cuantos, propios de un modo de producción y de vida que, sobra recordarlo, destruye cuanto haga falta a cambio de beneficios cuanto más rápidos mejor...

2) Porque comporta demasiado dolor. Dolor por la explotación de unas vidas absolutamente precarias, para las cuales vivir es siempre y sólo sobrevivir; dolor de los vecinos expulsados de sus barrios, cuando el centro de la ciudad se recupera para la industria del entretenimiento y la cultura; dolor de cuantos llegan con promesas de futuro y ven sus biografías convertidas en la narración de las nuevas formas de esclavitud; dolor de los jóvenes que envejecen sin poder crecer; dolor de los viejos que mueren de vergüenza de no poder comer.

3) Porque comporta demasiado engaño. Engaño de una Barcelona que se presenta a sí misma afirmando que es lo que en verdad no es; de una Barcelona-escaparate, cuya imagen competitiva, que llama a la inversión y al turista, esconde una brutal simplificación de su historia y de su memoria colectiva...

4) Porque comporta demasiada impotencia. Impotencia de quienes viven atrapados en la lógica de esta realidad, condenados a no poder más que elegir entre opciones que confirman una y otra vez el discurso con que se impone el nuevo capitalismo de ciudades y marcas.

5) Porque comporta demasiada mediocridad. Mediocridad de sus ambiciones, de su arquitectura infantilizada y de sus edificios emblemáticos, de su triste programación cultural, de sus políticos risibles, de su autosatisfacción de pueblo pequeño...

Injusticia, dolor, engaño, impotencia y mediocridad, son, en fin, los materiales que edifican una ciudad en la que la mayoría de sus habitantes tiene que hacer de su vida nada más que un medio de vida. Ciudad-laboratorio de un sistema al que, tengamos o no alternativas globales, no dejaremos de querer derrocar.

\section{La marca Barcelona y el fascismo postmoderno}

Lo esencial de la marca Barcelona es que se trata de un nuevo modo de dominación política. A este modo de ejercer el poder, y consecuentemente, a la forma de obediencia que le corresponde, lo hemos llamado fascismo postmoderno. Creemos que esta expresión es la que mejor le conviene. 
En la segunda parte de este informe analizaremos la lógica expansiva de la marca Barcelona, y, en concreto, sus tres mecanismos principales: 1 ) el proyecto, 2 ) el multiculturalismo (o movilización de las diferencias) y 3) la neutralización de lo político. Pues bien, al resultado combinado de estos mecanismos, a la realidad que resulta de su funcionamiento combinado, es a lo que denominamos fascismo postmoderno. El fascismo postmoderno reside en el corazón de la sociedad-red. Mejor aún: es su verdad. Con eso queremos afirmar que la red no es sinónimo de libertad, como algunas veces se nos quiere hacer creer.

\section{La red es un mecanismo selectivo, jerárquico y de control. Su verdad, la que día a día soportamos, se resume así: o te conectas o te mueres (socialmente). Esa coacción, esa obligación a movilizarse y a participar bajo amenaza de muerte, ese vivir sin otra salida que la permanente conexión, eso es el fascismo postmoderno: la participación que se confunde con la propia vida porque no deja otra salida.}

Por esa razón decimos que el fascismo postmoderno es una movilización total de la vida. Como en el fascismo clásico se trata de una verdadera gestión de la vida, una auténtica movilización a la que nadie escapa. Cada vida, todos, somos puestos a trabajar. Más exactamente: la movilización, que se confunde con vivir la propia vida, tiene como efecto producir esta realidad obvia que se nos cae encima. Esta realidad inapelable, dura y blanda a la vez, verdadero chicle al que estamos pegados. El fascismo postmoderno es la cárcel que nos encierra pero en la que somos libres, aunque nuestros cuerpos lleven la piel tatuada con la marca Barcelona. No debemos olvidarlo en ningún momento: "Tots som el motor de Catalunya" (Todos somos el motor de Catalunya), "Tots movem Barcelona" (Todos movemos Barcelona). El fascismo postmoderno es la movilización total de la vida por lo obvio. Pero si quiero yo puedo sentarme en una terraza para tomar algo. O ir a una manifestación contra la guerra. O quedarme en casa.

En el fascismo postmoderno no hay un Jefe ni un pueblo. En lugar del Jefe hay un poder informe que obliga autoobligando, que controla mediante el autocontrol. Que convierte la cultura en recurso propio. No hay propaganda, hay comunicación. El pueblo ha sido sustituido, asimismo, por un conjunto de individuos diferentes unos de otros. Del hombre masa del fascismo clásico hemos pasado al individuo que somos cada uno de nosotros. Cada uno buscándose a sí mismo, cada uno intentando construir su autonomía personal... cada uno simplemente viviendo. La movilización de la vida es, antes que nada, automovilización: uno mismo se motiva a sí mismo.

De ahí ya se puede deducir que el fascismo postmoderno consiste en la gestión del teatro de la vida. Ese teatro que está formado por vidas protagonistas (emprendedores), vidas hipotecadas (precarios) y vidas residuales (sombras). Gestión significa, evidentemente, (auto) movilización.

Pero falta aclarar un punto. El fascismo postmoderno no es un fascismo más blando. No hay que engañarse al respecto. El fascismo clásico movilizaba para hacer la guerra. Con el fascismo postmoderno se produce una inversión: porque se nos hace la guerra tenemos que movilizarnos.

Todos y cada uno somos el enemigo contra el que se dirige esta guerra que es la precarización de la vida. 
Porque podemos interrumpir la sociedad-red, porque podemos paralizar la (auto)movilización en cualquier momento y en cualquier lugar somos sus enemigos. De aquí que la forma Estado del fascismo postmoderno sea el Estado-guerra, ese Estado que construye su política como guerra a partir de la dicotomía amigo/enemigo. No es de extrañar, pues, que el autocontrol venga acompañado por un Estado policial, o que el multiculturalismo se despliegue paralelamente con leyes de extranjería. La lógica de funcionamiento del fascismo postmoderno no tiene la coherencia implacable del fascismo clásico. Al contrario, es una lógica paradójica que juega perfectamente con la confusión de posiciones relativas e incoherentes. Más allá de esta movilización, en el fondo no pasa nada. Porque cuando la realidad es obvia, efectivamente, no pasa nada. Esa realidad es la del fascismo postmoderno. 


\section{PRIMERA PARTE}

\section{EL FORUM UNIVERSAL DE LAS CULTURAS: LABORATORIO DEL FASCISMO POSTMODERNO.}

\section{Qué es el Forum}

Hay que reconocer que el Forum Universal de las Culturas que se celebra en Barcelona durante el año 2004 constituye una auténtica novedad. $\mathrm{Ni}$ es una variante de las antiguas Exposiciones Universales ni tampoco un espectáculo como los Juegos Olímpicos. Desde el día mismo en que fue anunciado y a lo largo de todos estos años hemos visto las enormes dificultades que encerraba su definición. Los sucesivos directores generales del futuro evento se mostraban incapaces de decir en qué consistía: encuentro de las culturas, manifestación por la paz, fiesta de la diversidad... Sin duda que esa dificultad tenía una causa, una razón que las autoridades, sin embargo, nunca han querido admitir. Digámoslo con claridad: el Forum Universal de las Culturas no es más que el modo de vender la marca Barcelona. ¿Pero cómo hacerlo sin decir que se trata justamente de eso? He ahí la fuente del problema.

La marca Barcelona ofrece un modelo social, un ejemplo de territorio que permite reunir y gestionar, con armonía y justicia, los recursos sociales -diversidad, participación, ausencia de conflicto- exigidos por el nuevo capitalismo. Presentar la marca, ponerla en escena, significa así poner en marcha -de manera simbólica- el Proyecto mediante el cual se construye y gobierna el territorio. En ese sentido, el acto de presentación consistirá justamente en levantar un escenario donde se represente el Proyecto, esto es, un espacio donde se reúna y gestione, con el mayor control, las condiciones ideales que permitan contrastar el modelo social, verificarlo. La marca se vende demostrando que es verdad.

Ahora bien, semejante lugar recibe, con todo rigor, el nombre de laboratorio. Así que eso es el Forum de las Culturas: el laboratorio del fascismo postmoderno, el espacio donde se muestra la verdad de Barcelona, mediante un acto de propaganda institucional dirigido tanto al público comprometido en la marca, sujeto a ella -el ciudadano de la metrópolis- como al capital interesado, por su propio beneficio, en invertir en un modelo así.

\section{Sobre la dificultad de la crítica}

La primera consecuencia de esta definición es que ya no valen las formas habituales de crítica. Es lo que estamos viendo. Se denuncia a las empresas ligadas al proyecto -Indra, etc.- porque participan en la guerra de Irak; se denuncia la especulación que ha generado su desarrollo; se denuncia el proyecto mismo como un circo de las culturas, etc. Está bien. Pero todas las denuncias del mundo no logran hacer mella en el Forum 2004, y lo sabemos. La condena de su hipocresía, el rechazo de su impostura, de su mentira, tampoco consiguen afectarlo. $Y$ es que esa es la novedad radical del acontecimiento: desarmar a la crítica, incapacitarla, volviendo siempre estrechos sus puntos de vista o empujándola hacia la defensa insostenible de las utopías, la autenticidad, etc. 


\section{La pregunta que debemos hacernos ante el Forum 2004 es entonces la siguiente: ¿Cómo criticar un discurso -político, cultural, económico- que se presenta con el lenguaje del no-poder para ejercer mejor el poder? Esta es la cuestión y la extrema dificultad a la que nos enfrentamos.}

El Forum 2004 es el laboratorio del fascismo postmoderno porque produce, como hemos dicho, una realidad obvia. Una realidad obvia es aquella que se construye mediante categorías obvias, mediante principios que solo un necio podría cuestionar. Conocemos bien los tres que conforman el Forum 2004: paz, diversidad y sostenibilidad. ¿Alguien podría oponerse a uno solo de ellos? Claro que no. Son las obviedades de lo políticamente correcto. Ante ellas no podemos más que asentir y cerrar la boca. Si además el Forum 2004 se presenta como una defensa del diálogo, como una llamada a participar incluso críticamente, entonces está claro que no hay lugar desde donde denunciarlo.

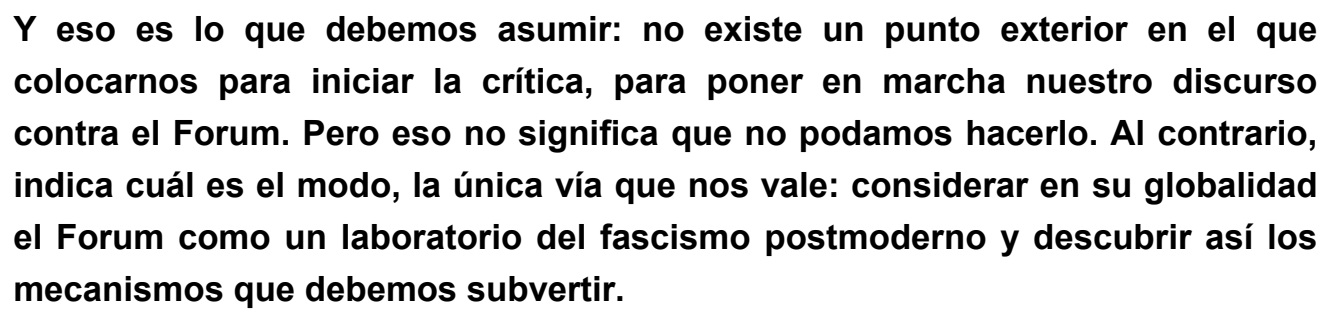

Al hacerlo comprenderemos que, más allá de una Expo de los valores o de una apología de lo políticamente correcto, el Forum es en un dispositivo de captura, tendido para apresar la única instancia realmente decisiva: nuestro querer vivir. En este sentido el Forum 2004 es, en efecto, un Acontecimiento, pero que consiste en anular todos los acontecimientos y, en especial, el que él mismo pretende provocar, a saber, el de un encuentro. Por el contrario, la verdad del Forum 2004, la que él mismo expresa poniéndola en marcha, es la de la soledad, la de los individuos solos, la del nosotros despolitizado, la de la sociedad impotente.

\section{La entrada en el laboratorio.}

El logotipo del Forum lo deja muy claro: hay que olvidar las manos que se cogen, que se tocan, que se llaman. Nada de manos exigiendo, acariciando, luchando. Toda esa iconografía de manos grabada en nuestro inconsciente cultural, se borra ante estas manos asépticas, inexpresivas, sin otra posibilidad que la mera conexión. El logotipo lo deja muy claro: entramos en un laboratorio.

Se trata de un laboratorio pagado con fondos públicos pero gestionado bajo el modelo y a favor del capital privado. Por eso, aunque se presente como un lugar abierto no lo es. Para entrar en el Forum hay que pagar. Por supuesto que existen muchos tipos de entrada. Casi tantos como quieran quienes deseen entrar. O según sean sus posibilidades económicas. El caso es que en la puerta hay un cartel que dice: "Reservado el derecho de admisión". Como también fue reservado el derecho de admisión durante la preparación del acontecimiento. Algunos sectores sociales se han quejado de ello. Es no entender de lo que se trata.

El Forum 2004 no es en absoluto el fruto de una discusión colectiva, ni de la experimentación de los movimientos reales de Barcelona. En este acontecimiento convergen el Ayuntamiento, la Generalitat y el Gobierno central. Se trata, por tanto, de una verdadera política de Estado. No en vano, el 


\section{sistema de partidos se ha mostrado unido como un solo hombre a la hora de defenderlo.}

La entrada se paga. Si la compras, adquieres un password que te permite asistir en primera fila al espectáculo. Es más, la entrada te da derecho a formar parte tú mismo del espectáculo. ¡Qué vieja se ha hecho la crítica situacionista! En el Forum 2004 no hay participantes pasivos puesto que todos los visitantes son miembros activos del espectáculo que ellos crean. Gracias al password tienes también la posibilidad de hacer zapping: comer un guacamole mexicano o bailar la samba con un simpático grupo brasileño. Tú mismo construyes el mundo imaginario en el que prefieres vivir. Pero la cosa no termina aquí. La combinación de password y de zapping, según dice la propaganda, da derecho a tener una experiencia única y divertida. Como nuestro alcalde afirma: "pasarán cosas diferentes, excitantes y profundas. Será intenso y divertido". Lo que no puede reconocer es que, en el interior de un laboratorio, la vida si de verdad existe es necesariamente vida manipulada.

\section{Dentro del laboratorio.}

En el Forum 2004 la marca Barcelona se despliega en su máxima visibilización. Cada conferencia, cada espectáculo, todo lo que ocurre, en definitiva, funciona para y por la marca Barcelona. Si como hemos analizado la marca Barcelona es una forma de dominación política, el Forum 2004 tiene que ser un laboratorio que muestre al mundo cómo se plasma este ejercicio del poder. Dicho directamente: el Forum 2004 es un laboratorio del fascismo postmoderno porque en él se (re)produce el fascismo postmoderno. No se trata de una metáfora. El espacio y el tiempo en los que este acontecimiento se concreta constituyen un verdadero laboratorio. Eso significa que el Forum 2004 tiene que cumplir unas normas:

\section{1) Esterilización del Otro.}

En el Forum 2004 el Otro está presente en cualquier lugar y en cualquier momento. El acontecimiento mismo es una fiesta de la diferencia. El Otro y la diferencia nos rodean. Las otras culturas, con sus músicas, con sus comidas, incluso con sus representantes colorean el paisaje. Porque aquí está la trampa: en el Forum 2004 el Otro que nos rodea no nos molesta. Si en el mercado podemos comprar café sin cafeína o nata sin grasa, aquí nos presentan también un Otro completamente esterilizado. El Otro no huele, tiene papeles y sobre todo no nos causa ningún daño. Es la falsa tolerancia del multiculturalismo liberal. Cada día llegan en patera inmigrantes ateridos de frío a los que aplicamos la ley de extranjería. En cambio, en el Forum, al Otro, al inmigrante, lo toleramos: le perdonamos la vida.

\section{2) Desinfección del espacio público.}

El espacio público en Barcelona, como sabemos, está crecientemente privatizado. Convertido en calles repletas de tiendas, pasear es lo mismo que consumir. No en vano nuestro Ayuntamiento pregona que Barcelona es "La botiga més gran del món" ("La tienda más grande del mundo"). Efectivamente, no hay espacio público: en un extremo, los medios de comunicación son el discurso de la unanimidad; en el otro, los bancos de las plazas se sustituyen por sillas unipersonales, cada uno mirando en una dirección distinta. En el Forum 2004 el espacio público ha sido desinfectado todavía más. Espacio sin conflictos, espacio seguro por encima de todo, espacio público especializado en 
serlo. En definitiva, museo del espacio público donde no hay vida porque no pasa nada que no esté previsto por una programación que busca recrear una polis inexistente.

\section{3) Rehabilitación del ciudadano.}

Un espacio público desinfectado sólo puede generar ciudadanos liofilizados. Eso es lo que en la realidad sucede. Los Juegos Olímpicos de 1992 perseguían fabricar un modelo homogéneo de ciudadano: el buen ciudadano. Ahora es distinto. La marca Barcelona nos necesita como activos intangibles, cada uno con sus propias capacidades. De aquí que el Forum 2004 fabrique no sólo ciudadanos normalizados sino sobre todo ciudadanos portadores de su propia diferencia específica. Al entrar en el Forum 2004 no se nos homogeneiza, al contrario, se estimulan la diversidad de gustos y de aficiones, porque la marca Barcelona se basa justamente en la riqueza de la diversidad, en la creatividad de la diferencia bien encauzada. El hombre anónimo es así desposeído de la fuerza del anonimato, el nosotros es reconstruido como un nosotros de individuos solos y aislados. Se rehabilita el ciudadano y, en el mismo momento, se le despolitiza.

\section{4) Inhibición del pensamiento.}

Casi no hace falta decirlo. El Forum 2004 inhibe el pensamiento. Tal como está organizado, tal como funciona, todo apunta a que el pensamiento sea imposible. El flujo de acontecimientos termina con el acontecimiento. La sobreabundancia de información mata la información. Pero no pasa nada. Todo se confunde con todo, todo se iguala en la banalización. Pero no pasa nada. El Forum sólo pretende exorcizar el vacío, que puede llegar a ser peligroso, llenar de emoción el instante presente. Nada que ver con el pensamiento. La constante llamada al diálogo y a la comunicación esconde la ausencia de pensamiento. Porque el pensamiento no nace del diálogo que tiene lugar en una conferencia con alguien famoso. No, el verdadero pensamiento surge cuando nos enfrentamos a nuestros verdaderos problemas. Eso es lo que el Forum 2004 impide porque se basa precisamente en la expropiación de nuestros problemas.

Por todo ello bien podemos concluir que el Forum 2004 es una laboratorio del fascismo postmoderno. Auténtica movilización total de la vida por lo obvio, producción de subjetividades despolitizadas. Acontecimiento esencialmente tramposo: diálogo que no es diálogo, Otro que no es Otro... Mentira de la mentira del mundo. 


\section{SEGUNDA PARTE}

\section{ANÁLISIS DE LA MARCA BARCELONA}

\section{BCN: una creación colectiva expropiada.}

Cuando decimos que Barcelona se ha convertido en la marca Barcelona nos referimos ante todo a un fenómeno de marketing. Si se pone una marca a algo, es para identificarlo. Es el modo más directo de apropiárselo. La marca expresa que lo marcado ya tiene un dueño y que, por tanto, no es tuyo. En otras palabras: que si lo deseas debes comprarlo porque está claro que no te lo darán.

\section{Asociar la marca a Barcelona indica así, antes que nada, que la ciudad ya no pertenece a quienes habitamos en ella.}

No se trata de que seamos turistas en nuestra propia ciudad. Si fuera únicamente eso hablaríamos de una simple sensación. Lo que la marca Barcelona expresa es que la ciudad pertenece al capital. Que toda ella está concebida y construida para que el capital pueda valorizarse y multiplicarse. La marca nos desposee así de lo nuestro. No es que antes Barcelona fuera nuestra, pero sí que podía -y, en ciertos momentos, conseguía- llegar a serlo. Aunque sólo en ciertos momentos, cuando la calle era una fiesta de fuego. ¿Alguien se acuerda de la "Rosa de foc"? Si la marca Barcelona fuera solo una imposición exterior sería fácil rechazarla. Lo que ocurre es que se trata de una auténtica creación colectiva, expropiada por el capital mediante un instrumento, la marca, que es un fenómeno comercial pero sobre todo comunicativo.

En efecto, la marca moderna -y Barcelona lo es- aparece cuando los productos pasan de "servir" para algo a "significar" algo. Entender este cambio exige, en primer lugar, dejar a un lado el antiguo modelo de oferta y demanda, que precisaba de un consumidor pasivo. En este antiguo modelo la comunicación se reducía a una publicidad, cuya única función consistía en aumentar las ventas. La marca de entonces tenía que ver con una oferta-producto. Con la nueva marca, en cambio, estamos ante una oferta-comunicación. Más que ofrecer un producto, la marca aporta elementos inmateriales y discursivos. No hay consumo sino recepción. La nueva marca requiere una acción interpretativa, de cooperación, creativa. Por eso tampoco hay consumidor sino público. En este sentido, si la marca Barcelona compite con las otras ciudades en el mercado de las marcas es porque estamos nosotros, su público. Eso no significa que la marca Barcelona haya sido diseñada en un despacho, por un acto individual. En absoluto. Más bien es el resultado de un conjunto de prácticas económicas, políticas y culturales, esto es, de un entramado comunicativo que integra en su interior al público mismo. En este sentido, las manifestaciones masivas contra la guerra de Irak, por ejemplo, contribuyeron a la creación y reafirmación de la marca Barcelona tanto como la política urbanística del Ayuntamiento.

\section{$\mathrm{BCN}$ : una máquina productora de sentido.}

El funcionamiento de la marca Barcelona no se ajusta a la explicación común de la relación entre publicidad y consumo. Como fenómeno comunicativo va mucho más allá. La marca Barcelona es una máquina productora de sentido. Su combustible está formado por nombres, colores, sensaciones, sueños... En vez de disolver todo proyecto vital en una serie, sin presencia ni historia, de bienes de 
consumo, su resultado - si la máquina funciona bien - es un mundo ordenado, estructurado y atractivo del cual todos participamos. Este mundo no es unitario sino que está hecho de una multiplicidad de mundos, tantos como relaciones puedan establecerse con la marca Barcelona. Paradójicamente, cuanto más vaga sea la idea general de la ciudad mayor será la singularidad del mundo posibilitado por aquella relación. $Y$ es que la marca Barcelona tiene la facultad, como todas las marcas modernas, de construir mundos posibles y dotarlos de sentido.

Habitualmente se dice que la publicidad no se cree (hacemos como si fuera verdad) pero que nos adherimos a lo que nos ofrece. En cambio, ante la comunicación de la marca Barcelona, el público se adhiere directamente a ella porque quiere creer en ella. Después de la crisis de las propuestas de emancipación ¡hay unas ganas tan enormes de creer en algo!

\section{La marca Bar-cel-ona, con sus olas, con su cielo... nos devuelve el proyecto vital, el horizonte de sentido que no encontrábamos. Disfrutarla puede ser una tarea inacabable. ¿Se puede pedir más? La marca Barcelona construye mundos imaginarios en los que habitar y así consigue legitimarse.}

Bien es verdad que la marca Barcelona, como cualquier otra, no se autoabastece, no dispone de una fuente de oxígeno propia. Requiere de nuestra implicación, es decir, necesita establecer relaciones de complicidad, adhesión y afecto seguras y fuertes con todos nosotros, su público. La marca Barcelona está obligada a reafirmar constantemente su existencia. Frente a las otras ciudades. Frente a nosotros. Porque si no produce sentido, si no nos ofrece proyectos - y ella misma se despliega, como veremos ahora, a golpe de proyectos- se difumina.

\section{BCN: el nombre de una ciudad-empresa.}

Toda marca busca establecer un contrato de preferencia con su público y conseguir así que le sea fiel. Credibilidad, legitimidad y afectividad son las condiciones que la marca debe cumplir si quiere seguir siendo elegida. La marca Barcelona es, sin embargo, una marca muy especial. De entrada, porque la ciudad de residencia casi nunca se escoge: se nace o se vive en ella, simplemente. O se llega a ella persiguiendo alguna promesa. En ese sentido parece poco apropiado hablar de un contrato de preferencia, por más que una economía globalizada, no lo olvidemos, empuje a cambiar de ciudad e incluso de país.

Ahora bien, que no exista semejante contrato no significa que la marca Barcelona no deba producir igualmente legitimidad, credibilidad y afectividad. El modo de hacerlo es mediante campañas puestas en marcha por las instituciones. Desde la que se organiza periódicamente a favor del civismo hasta la fiesta mayor, concebida ya como una campaña, todas ellas tienen un doble objetivo: por un lado, asegurar los recursos mencionados arriba; por otro, construirnos a todos, convertirnos a todos en sujeto de la marca. Dicho de otro modo:

no somos nosotros quienes escogemos la marca Barcelona, es ella la que nos escoge a nosotros. Desde esta perspectiva la marca Barcelona actúa como una norma: dice qué cabe en ella y qué debe ser excluido. $Y$ lo dice en todo lugar y en cualquier momento, en el metro y en la plaza pública.

Es cierto que la norma generalmente actúa disciplinando, produciendo individuos sujetos a ella, es decir, normales. Pero la marca Barcelona es posmoderna, de modo que aunque produzca individuos 
según una norma no por ello los homogeneiza. Esa es justamente su novedad. La marca Barcelona produce diferencias, o sea, hombres y mujeres considerados libres.

¿Cómo puede ser que la norma no homogeneice? ¿Cómo puede ser que la norma lejos de plegarnos a un único patrón -normalizado- nos deje a cada uno ser en nuestra diferencia?

La respuesta más rápida, y en la que profundizaremos después, es que paradójicamente la norma que se ha tomado como norma es el movimiento. Movimiento, o mejor, movilismo generalizado.

Esta es la consigna de todas las campañas institucionales desde hace años. "Tots som el motor de Catalunya. No paris" (1995), "Una trobada que mourà el món" (2004), "Tots movem Barcelona" (2004). El arquitecto jefe del municipio lo dijo ya con acierto hace un tiempo: "La ciudad es como una bicicleta. Puedes pedalear deprisa o despacio, pero si no pedaleas te caes". (J. Acebillo, El País, 1511-2003). Movilismo o flexibilidad. En el trabajo y en nuestra vida. La gestión de la marca Barcelona es, en definitiva, la gestión de nuestras propias vidas mediante la movilización de su precariedad. Así que sólo podremos liberarnos, dejar de estar sujetos a la marca, si nos atrevemos a caer. Aunque toda caída haga daño.

A continuación analizaremos la marca Barcelona a partir de sus tres principales mecanismos de funcionamiento: 1) la articulación de la ciudad como proyecto, 2) la ideología del multiculturalismo y 3) la neutralización de lo político.

\section{Primer mecanismo: BARCELONA COMO PROYECTO.}

\section{El capitalismo del conocimiento y la metrópolis.}

El capital acude allí donde la riqueza y diversidad de las conexiones, del tejido cultural y formativo, favorece la producción de ideas. O, viceversa, el modo de atraer capital consiste en gobernar un tejido social que por su condición heterogénea, plural, móvil, abra la expectativa de una creación sostenible de ideas. Pues bien, para decirlo de una vez:

\section{desde hace veinte años Barcelona ha dejado de ser una ciudad "moderna" en sentido histórico, un espacio para la expresión política de los conflictos de la sociedad industrial (la lucha por el reparto social del beneficio), y se ha transformado en un territorio donde se acumula y gobierna, con criterios puramente empresariales, la posibilidad misma de ese nuevo recurso del capitalismo que es el conocimiento.}

Hemos visto que la actividad mercantil implica siempre un acto comunicativo, que toda mercancía envuelve un intercambio de información. Esto es así porque en un contexto de saturación del mercado las empresas deben no ya intensificar su propaganda sino asumir socialmente un discurso propiamente institucional: quién soy, qué hago, a quién me dirijo, con qué fin. En una palabra: cuál es mi proyecto. En este sentido, las relaciones económicas son también relaciones de signos.

Ahora bien, la información existe en la forma social que llamamos sociedad red. Esto implica, de entrada, que el acceso a la información tiene que efectuarse siempre en forma de conexión; y, 
segundo, que es imposible disponer a la vista de toda la información. Por principio la red está hecha de bordes, vacíos, intersticios que se articulan y extienden en configuraciones reversibles e ilimitadas.

Bajo estas condiciones, dar con un nuevo producto, ofrecer un nuevo servicio, pasa literalmente por tener una idea: saltar un vacío, crear una conexión, establecer un vínculo inédito entre puntos o nodos de información relativamente densos y estables, abrir, en fin, una asimetría. Así, concebir una idea provoca en la red una contracción espacio-temporal que modifica sus trayectorias relativas y comprime sus intervalos: tengo lo que quieres, sé como hacerlo, ahórrate el tiempo.

La idea atrae a un capital ansioso de oportunidades. En efecto, su apropiación (en forma de patentes $\mathrm{u}$ otros medios de propiedad intelectual) abre una ventaja competitiva, un diferencial de enorme potencialidad. Lograr su materialización, esto es, explotar la idea, rentabilizarla en términos empresariales, define la función y el objetivo asumidos por el proyecto, articulación central de este capitalismo cognitivo. El aflujo del capital entorno al proyecto pliega entonces la red sobre una zona activa, creadora de valor, una bolsa de acumulación que reconfigura de forma inédita la circulación de mercancías, de signos, de dinero.

\section{La singularidad de Barcelona: un Proyecto de proyectos.}

Concebir la ciudad como una empresa cuyo proyecto sea justamente producir proyectos que atraigan a las empresas; gestionar el territorio con vistas a producir las condiciones mismas de productividad que impone hoy el capitalismo: ese es el reto de Barcelona. No se trata de destacar en tal o cual mercado, de reconvertir su infraestructura adaptándola a un sector u otro, de ofrecer, en fin, condiciones especificas de rentabilidad y seguridad al capital. En nada de eso compite especialmente Barcelona, y lo sabe. De lo que se trata es de asegurar las condiciones ideales requeridas por la nueva sociedad, asumiéndolas como objeto de un discurso político-empresarial que dirija hacia el propio territorio, sobre el tejido social mismo, tanto la acción de gobierno como la inversión económica. El desafío barcelonés es producirse a sí misma como expresión ideal de la sociedad del conocimiento, no en la forma depurada o abstracta del Sillicon Valley sino con toda la complejidad social de las nuevas metrópolis.

No hablamos, pues, de que Barcelona, como el resto de las regiones metropolitanas, sea ya una ciudad empresa articulada por proyectos.

\section{Barcelona misma es un proyecto. Un proyecto que consiste en dar realidad efectiva, ejemplar y concreta, al modelo de relaciones sociales ideal para el capitalismo cognitivo. Concebido así entre el foro de Davos -el neoliberalismo contra la sociedad- y el de Porto Alegre -la sociedad contra el neoliberalismo- el modelo barcelonés encierra un valor político esencial para el futuro del sistema.}

La capacidad de generar proyectos, de suscitar ideas productivas, no puede ser "producida" del mismo modo que un proyecto o una idea concretos. Así, más que una empresa stricto sensu el Proyecto Barcelona define la inversión fundamental, la estrategia constituyente absoluta de todas las instancias -empresariales y administrativas, públicas y privadas- a las que soporta y representa: proyecto, pues, en sentido trascendental, sin otro objeto que sí mismo como condición de que haya en general proyectos; sin más producción, en fin, que la de sí mismo como espacio de posibilidad de 
la institución empresarial y gobernado, a través del Ayuntamiento, por un complejo político-económico cuyo esquema analizaremos después.

De momento, y manteniéndonos en ese nivel fundamental, constitutivo, destacaremos cinco dimensiones del Proyecto:

- -Imaginaria: ante todo, el Proyecto Barcelona ofrece a quienes participan una imagen de sí mismos, un espejo en el que reflejarse, una identidad donde poderse reconocer. $Y$ es que vivir en Barcelona no significa ya tener una historia, inscribirse en la trama que tejen sobre el espacio urbano las relaciones de producción. Ni el trabajo ni la vida remiten ya a una instancia colectiva, capaz de hablar y decidir por sí misma, autónomamente. En su lugar, la reconversión de los años 80 ha dejado sólo vidas anónimas, despolitizadas, vidas a la deriva por el territorio metropolitano. Para ellas, el Proyecto Barcelona representa no solo una forma -chantajista- de obtener riqueza, de atraer capitales, sino el único acceso a un espacio social compartido, a un ámbito de relaciones común. Reconvertida en proyecto, la ciudad devuelve a sus habitantes la posibilidad esencial de un "formar parte", pero limitada a una sola manera: participar. Al fin, ser de Barcelona significa algo, para uno mismo y ante el mundo; algo reconocible por todos. Consiste en el puro ser-partícipe como condición o atributo de la nueva ciudadanía. El Proyecto Barcelona se revela entonces como la forma imaginaria que permite a los ciudadanos constituirse, entrar en relaciones, decir quiénes son, reconocerse, salir del anonimato, orientar su vida, construir sus propios proyecto: conectar.

- Normativa: si bien el capital controla en última instancia las relaciones sociales y el espacio de comunicación, se trata de un dominio a distancia, de un poder que funciona como función estratégica, respetuosa y atenta a las condiciones del tejido social - diverso, heterogéneo, móvilsobre el que interviene. De lo que se trata, en definitiva, es de dar una forma "rentable" a lo social difuso de la metrópoli. Esto nos sitúa en el contexto de la producción postfordista. Una vez más, Barcelona lo ha visto muy claro y ha asimilando la larga experiencia de la gestión empresarial $-y$ su clave maestra: el proyecto- a los términos de un discurso directamente político. El Proyecto Barcelona se muestra así como la instancia de gobierno formalmente adecuada al capitalismo del conocimiento. Evitar la dispersión, funcionar en sinergia, salvar la fluidez pero tomando cuerpo, haciendo comunidad, reuniendo: tal es, en efecto, el orden que garantiza.

En ausencia de jerarquía, de cadenas de mando rígidas, disciplinarias, el Proyecto Barcelona extiende sobre el territorio una red, una lógica que subsume la miríada de conexiones, de actos comunicativos, en una forma coherente y dinámica. En este sentido, su "esto somos, así hacemos" se resuelve en una provisión de consignas que, por su misma naturaleza, provocan el reconocimiento -y la circulación de quienes las repiten. No se trata ya, como vimos al hablar de la marca, de campañas institucionales, ni de exhortaciones genéricas a la participación, ni de expresiones de aliento más o menos retóricas. Nos referimos a verdaderas consignas, retransmitidas sin interrupción y en situaciones de habla cotidianas, hasta formar un lenguaje, un sentido común, una red de signos específicamente ciudadana.

\footnotetext{
El Proyecto Barcelona produce así el consenso remitiéndolo, no al principio de negociación, sino al respeto de un código innegociable, severa e implacablemente político: participas o no, te conectas o no, estás o no en esto, con nosotros o contra nosotros.
} 
- Simbólica: el discurso postfordista reconoce también que, alcanzado cierto nivel en el desarrollo del mercado, el aumento de productividad depende ya de la gestión de las personas, del capital humano. Movilizar las energías, los recursos psíquicos, las capacidades relacionales -cognitivas, emocionales- de su personal constituye así, como sabemos, un objetivo prioritario tanto de la nueva empresa como del espacio metropolitano gobernado a su imagen. Ahora bien, concebido en términos de pragmática lingüística, comunicar un proyecto implica precisamente ponerlo en marcha, suscitar la adhesión, llamar a la participación, "activar". En efecto, una vez comunicado, el proyecto no deja en general espacio para otra relación: o te adhieres a él -vital, incondicionalmente- o te excluyes. En este sentido, el Proyecto Barcelona, precisamente por serlo, provoca con su declaración una movilización total del territorio. Más allá de su expresión literal y del acierto de sus lemas, la retransmisión de consignas en que se resuelve el Proyecto permite, tanto por su función normativa como por su efecto de movilización, asimilar el cuerpo social de la metrópolis al de las órdenes militares, con todas las consecuencias intuidas en la afirmación. Barcelona tiene aura - además de voluntarios...

- Temporal: Articulándose en objetivos que regulan su desarrollo, el Proyecto Barcelona da a la ciudad -al espacio social, a las vidas que moviliza- un ritmo, una secuencia, que permiten la tensión y reapropiación del tiempo. Por un lado, el calendario festivo o ritual de la ciudad es absorbido en una nueva liturgia que lo gestiona en ceremonias de participación. Pueden ser parciales, barrio a barrio, diferencia a diferencia: Día de la Bici, del Comercio Justo, de los Afectados de Ritinosis... O pueden ser generales, en la exaltación de un uso lúdico y cívico del llamado "espacio público". Luego están los eventos políticos, reacciones más o menos previsibles ante el curso no tan previsible del mundo: cumbres, guerras, atentados, etc. Son eventos que se agotan en su manifestación y que acaban redundando en el Proyecto, como exhibición de su potencial de movilización. Por último está el Acontecimiento, allí donde el Proyecto Barcelona se muestra sin mediaciones, se vuelve inmediatamente sensible, perceptible, y del que el Forum ofrece, como veremos, una expresión ejemplar. Forma sin contenido (no pasa nada), presencia de un mero espacio de posibilidad -de encuentros, de conexiones-, el Acontecimiento se revela como una pura flexión de tiempo, capaz de plegarlo, de tensarlo. Disuelve su opacidad -el "no futuro"- y provoca la aparición del sentido, su donación absoluta.

- Cognitiva: La profusión de ideas suscitada por el proyecto -“Comunícate, piensa, habla"encierra tanto un problema de valoración, de discriminación (qué ideas valen y cuáles no, qué ideas son rentables y cuáles no) como un peligro de contención, de seguridad (qué ideas pueden subvertir o dispersar su propio espacio de posibilidad). En ambos casos, el Proyecto Barcelona representa un enunciado central, capaz de acumular significativamente el conocimiento que origina su propio dinamismo: selecciona e invierte en aquellos proyectos que lo fortalecen y bloquea por el contrario los que tiendan a comprometer su propio carácter, esto es, su rentabilidad.

\section{El Ayuntamiento-empresa}

La creación, el desarrollo y la implementación de este Proyecto Barcelona han requerido de un nuevo modelo de gestión de la ciudad y de los instrumentos para llevarlo a cabo. En gran parte ambos han sido proporcionados por el propio Ayuntamiento. Gracias al intenso proceso de cambio interno, organizativo y estructural y a una reorientación estratégica profunda desarrollados a lo largo de los 
últimos veinte años, el Ayuntamiento se ha convertido en el núcleo efectivo en la gestión del Proyecto-ciudad.

Este proceso de transformación ha ido encaminado fundamentalmente a situar al Consistorio como nodo de conexión entre, por un lado, los recursos públicos propios de la institución municipal y el capital social de la ciudad, y, por el otro, la iniciativa privada de diversas empresas y corporaciones. Dicho con una imagen,

\section{el Ayuntamiento se ha convertido en el webmaster (administrador del sistema) idóneo para el nuevo capitalismo informacional: un rol que, como veremos, va mucho más allá de poner los recursos municipales al servicio del capital privado.}

De entrada, y en su línea de actuación más conocida, el Ayuntamiento ha promocionado la colonización del espacio físico, comunicativo, cultural y social de la ciudad por parte de empresas privadas. Lo ha hecho facilitando la creación de nuevas empresas (Barcelona Activa) o allanando el terreno para el aterrizaje de las grandes corporaciones en proyectos de remodelación urbanística del territorio urbano (Iniciativas SA). Además, desde la segunda mitad de los 80 ha ido dejando paulatinamente el marco tradicional de sus competencias para erigirse en gestor y moldeador de prácticamente todos los aspectos de la vida urbana. Así, de limitarse a los servicios públicos a su cargo (agua, basuras, etc) ha pasado a administrar los recursos heterogéneos del territorio metropolitano. Ejemplo de rigurosa biopolítica, el Ayuntamiento gestiona ya toda la vida urbana. Se puede constatar fácilmente observando los grandes ámbitos temáticos de la web municipal: turismo, negocios y servicios.

Este papel clave del Ayuntamiento en el proceso de revalorización del capital que culmina, como hemos visto, en la creación y marketing de la marca Barcelona ha supuesto asimismo una transformación en el tipo de organización municipal. Se ha pasado de la institución burocrática clásica a un modelo de organización empresarial, imprescindible a la hora de flexibilizar el alto grado de relación con el capital privado y el tejido empresarial. En una palabra, la incorporación del territorio al Proyecto de ciudad-empresa ha exigido que también el Ayuntamiento, y de modo ejemplar, se haya convertido en empresa. Los procesos han sido los siguientes:

1. Se ha producido una intensa gerencialización de la estructura institucional. Se ha simplificando la jerarquía de las cadenas de mando y se ha introducido la figura del gerente directivo de alto rango no funcionario- en numerosos servicios y "regidories". De esta manera, gran parte de las decisiones políticas han quedado reducidas al ámbito técnico y han quedados resguardadas, por tanto, en una tranquilizadora opacidad.

2. Se ha ejecutado una reforma de los procesos internos conforme a los principios de la gestión empresarial -eficiencia, economía y eficacia- y a las innovaciones que aportan las tecnologías de la información y la comunicación. De hecho, el sistema nervioso del ayuntamientoempresa es ya una compleja red de sistemas de información, bases de datos y procesos automatizados. Son las herramientas de su proceso de gerencialización. Se ha pasado de la contabilidad presupuestaria, tradicional en las administraciones públicas, a la contabilidad financiera, próxima a los mecanismos contables de la empresa. El giro ha tenido entre sus consecuencias una política de personal muy agresiva, que se ha traducido, por ejemplo, en la violenta reducción de las plantillas y en el aumento exponencial de la subcontratación de 
numerosos servicios públicos a empresas externas. De forma paralela, la presión sobre el funcionario municipal ha acusado los cambios en el concepto de trabajo propios del postfordismo. Se ha potenciado así la figura del empleado polivalente, sin control efectivo sobre los procesos productivos (atributo clásico y aun esencial del funcionario) y obligado a un esfuerzo de formación continua del que depende su propia subsistencia en la organización. Por otro lado, se han introducido los niveles de productividad -en los procesos y en las personas como factor de evaluación del trabajo y como requisito para el ascenso o la promoción. Con ese fin han tenido que establecerse indicadores tan absurdos como, por ejemplo, el número de multas puestas por un agente de la guardia urbana, curioso factor de productividad que acaba haciendo real la leyenda que ha habido siempre al respecto.

3. El fenomenal auge de la externalización ha implicado la búsqueda de mecanismos capaces de articular relaciones más flexibles entre el capital público y el privado. En esta línea, se ha promovido la creación de un gran número de organismos autónomos y de empresas, bien de capital mixto, bien públicas. Son empresas creadas con capital extraído directamente de las arcas municipales, pero que funcionan estructuralmente como empresas privadas. Así define el Ayuntamiento su nuevo modelo de relación con los habitantes de la ciudad. Así se transforma de administración que ofrece servicios públicos a la ciudadanía en empresaayuntamiento, que provee a sus clientes de servicios cada vez más privatizados.

4. Como empresa proveedora, el ayuntamiento ha ejercido una gran presión sobre sus propias estructuras, tratando de "costumizar" al máximo los servicios que presta. En ese sentido ha utilizando de forma sistemática todo tipo de información sobre sus clientes (que lo son a la fuerza, esto es, cautivos), siguiendo la última línea empresarial: para una demanda diversa, una oferta de servicios igualmente diversa y personificada. Así ha ido definiéndose un nuevo tipo de ciudadano, cuyo papel como sujeto político queda desplazado por el de consumidor de servicios, esto es, por el de cliente de la administración. La construcción de esta nueva figura ha sido concebida con el fin de que el ciudadano mismo se haga corresponsable de las funciones públicas ejercidas por el Consistorio. La reconversión de aquella estructura burocrática ya obsoleta se facilita precisamente transfiriendo parte de la actividad administrativa y de sus responsabilidades a la propia ciudadanía. Con lo que el ayuntamientoempresa se apoya, de hecho, en una legión de ciudadanos-empresa, a quienes debe administrar los recursos y la información necesarios ("el calendario del contribuyente", por ejemplo) para gestionar sus propios trámites y necesidades.

5. Regresando al Proyecto Barcelona, hay que señalar los proyectos que bajo el epígrafe de "participación ciudadana" han sido expresamente utilizados por la propaganda institucional del Consistorio como medio de legitimación. Hablamos de una estrategia que, transformando o anulando la idea de participación política, se dispone a reconducir, mediante canales hiperformalizados y normalizados, aquella conflictividad social que pudiera interferir el despliegue del Proyecto-ciudad o de alguno de sus emblemas. Esta forma de sustraer la decisión política de los administrados mediante su reconversión a inputs de un canal diseñado y compactado tecnológicamente, así como limitado a temáticas concienzudamente elegidas por la administración, se hace si cabe más evidente en los llamados "proyectos piloto" o "experimentos de participación". Por lo que tienen de formulación explícita, convierten al ciudadano en poco más que un objeto de laboratorio para la ingeniería social. Cuando la voluntad de "participar" se escapa a los canales preestablecidos por ese aparato 
de diseño social, el conflicto deviene un simple problema de orden público. Se confía entonces a la actuación policial de la guardia urbana la responsabilidad de promover la participación ciudadana.

\section{Proyecto y movilidad. El nuevo escenario social.}

Vivir es conectarse a la red y solo hay un modo de hacerlo: participar en un proyecto, es decir, intervenir con la propia vida en la circulación de capital. En este sentido, el Proyecto Barcelona asume y gestiona como un bien social la nueva institución capitalista. Adecuar el territorio a las condiciones ideales de la sociedad del conocimiento significa incrementar el capital social de la ciudad, su conectividad general y la diversidad y riqueza de sus redes.

En la medida en que se da reconocimiento a los participantes ("La Barcelona que hacemos entre todos"), nos encontramos ante un nuevo criterio de justicia, ante un nuevo principio de legitimidad y política social del que el Proyecto Barcelona se declara pionero. Por eso podemos decir que el proyecto es en general inseparable de las personas que lo gestionan y a las que concierne. Si la red libera virtualmente los flujos de capital, el proyecto los constriñe de nuevo a las posibilidades de la existencia humana. La finitud del sujeto, su cualidad de estar ahí, definiendo el lugar y el momento que necesariamente ocupa, limita por principio las posibilidades de relación, de contacto, de experiencia. Las oportunidades y las expectativas de negocio transcurren ligadas al curso de una vida. Por eso hay que evitar las conexiones redundantes: el tiempo que se pierde en ellas no puede recuperarse.

El Proyecto Barcelona da origen entonces a una nueva división social que transforma la ciudad en el escenario de una nueva dramaturgia:

a) Teatro de emprendedores. Son los protagonistas. Son los dueños de un capital social rico en redes, en agujeros estructurales, en asimetrías informativas, un capital, en fin, que asegura su vida garantizándoles la movilidad, esto es, la capacidad de participar en el diseño y gestión de proyectos. Hablamos, pues, de un capital social literalmente incorporado a su persona: cúmulo de experiencias, de contactos, de referencias versátiles, dispuestas a producir ideas, a franquear dominios institucionales muy alejados. La suma movilizable de esas competencias define sus opciones de promoción, que siempre es transversal (pasar de un proyecto a otro), sus recursos de empleabilidad, su posición, en fin, en el sistema social.

Este nuevo arquetipo, insensible a la división entre ocio y trabajo, para quien toda relación personal es virtualmente productiva, puede compararse con el del artista bohemio, igualmente desregulado, ajeno a las convenciones e impelido por eso mismo a una vida absolutamente creativa. Para ambos el fin es el mismo: tener una idea, provocar una contracción, suscitar un proyecto y firmarlo. En este sentido, tanto el imaginario del Proyecto Barcelona -con su Mediterráneo de cartón piedra- como el del Forum de las Culturas están construidos con un discurso del mestizaje que lo muestra no como efecto de relaciones de poder violentísimas -el colono cubriendo a sus indias- sino como condición de ese simulacro de creatividad que llamamos fusión. Esto es lo que permite, como veremos, olvidar el lugar real de los inmigrantes en relación con el Proyecto.

Cierto que ambos, el emprendedor y el artista, mantienen en su origen relaciones opuestas con el capitalismo, pero la analogía resulta válida en la medida en que, en referencia al proyecto, el emprendedor no figura como propietario. Activa la circulación de capital como los productores y 
directores de cine: por su talento para crear conexiones de las que, por principio, no es dueño. Claro que su realización depende al fin de las empresas que las exploten, que materialicen el proyecto, pero se trata de un momento secundario -también en términos de beneficio- respecto al de la concepción del vínculo, de la idea.

Esta dependencia del capital respecto a la instancia creadora, cognitiva, es justo lo que el Proyecto Barcelona ha sabido poner en escena magistralmente.

b) Teatro de marionetas. Son los precarios, aquellos cuya pobreza de capital social condena a una precariedad sometida al ritmo de la hipoteca. La falta de contactos, la formación escasa o muy especializada, la estandarización de las experiencias, reducen la productividad de estos sujetos, su creatividad, la plusvalía potencial de sus conocimientos. Atrapados en relaciones localizadas, densas y cortas, sin apenas nada más que el lugar -geográfico o social- que necesariamente ocupan en el territorio, son ellos quienes fijan de manera estable los nodos vinculados a los desplazamiento de la actividad conectiva del emprendedor. Sin su inmovilidad no sería posible el salto, la asimetría, la idea: el Proyecto Barcelona. Clavados, pues, a la periferia material, "externalizada" de los proyectos, son ellos en cambio quienes otorgan, como los títeres, representación, consistencia, presencial real a los gestores de capital o conocimiento que, por principio, permanecen ilocalizables.

Vidas anónimas, redundantes, a las que nada ocurre ni se les ocurre, marcadas por auténticas minusvalías comunicativas -demasiado jóvenes, demasiado viejos; demasiado familiares, demasiado solitarios-, la precariedad es el precio que este nuevo proletariado debe pagar -iy cómo!- por los servicios del capital, esto es, por obtener una participación en el Proyecto Barcelona. Indefenso, sin la menor posibilidad de negociar, aceptará la función de soportarlo materialmente. A fin de cuentas no tiene a donde ir: no puede moverse.

c) Teatro de sombras. Son los otros, los desconectados, las vidas sin rostro, sin suerte, sin papeles: el residuo. Arrojados de pronto a un mundo para el que no están preparados, sometidas sus relaciones, pues, a un régimen de fuerza despiadado, sobre el que nadie les advirtió, agonizan por debajo del umbral de la comunicación socialmente rentable, significante. Nadie los conoce. La red no puede registrarlos, no tienen nada que decir ni que vender, así que solo por el testimonio de otros más compasivos, más "solidarios"- percibimos apenas su silencio. Fracasados escolares, trabajadores caídos en desgracia, inmigrantes extranjeros, mujeres despertadas a golpes, sus cuerpos se desplazan por los arrabales del imperio -mirando al mar, margen derecho- o entre los departamentos de "bienestar social" -un sarcasmo...

Las sombras representan, con su desconexión, la posibilidad aciaga pero esencial de la sociedad red, esto es, de un mundo construido sobre puras conexiones. Así que es el miedo, el miedo a su presencia fantasmal, amenazante, lo que nos hace movernos, lo que impulsa y sostiene nuestras vidas, lo que decreta, en fin, la movilización general.

Sólo el miedo a las sombras permite, en efecto, que toda conexión, porque consigue conjurarlo, se vuelva feliz, afortunada, incluido el cepo de un trabajo asalariado o una hipoteca para treinta años. Por miedo aceptamos participar en esto. El miedo es el motor del Proyecto Barcelona. 


\section{La movilidad sostenible como objeto y condición del Proyecto.}

Hemos visto que la incorporación al Proyecto, lejos de negociarse políticamente, se efectúa bajo la amenaza de la exclusión absoluta, esto es, al límite de una vida propiamente "humana", social. Y es precisamente ahí, sobre esa línea de sombra, donde interviene el sentido de justicia social del que el Proyecto Barcelona se reclama pionero y sobre el que funda su doctrina de la movilidad sostenible: cómo evitar el colapso, la anomia, el autismo, la incapacidad para tejer o renovar vínculos que garanticen la conectividad.

1) De entrada, el Proyecto Barcelona extiende por el territorio metropolitano una miríada de asociaciones, "espais" y forum; aulas, "trobades" y asociaciones -no gubernamentales, vecinales, de autoayuda-, que tejen sobre la ciudad una auténtica red virtual de intervención. Virtual: ya sabemos que en realidad están vacías pero eso no afecta a su poder de prevención, esto es, a su capacidad para operar eventual y quirúrgicamente sobre el límite de la conexión social.

2) Por otra parte está el reciclaje infinito, impulsado sin descanso por la red institucional del Proyecto mediante un programa incesante de cursos, jornadas y seminarios debidamente certificados. Y es que, ante todo, el ciudadano-partícipe es cursillista. El contenido de los cursillos es lo de menos. Todos saben que no se aprende nada, y aunque no fuera así da igual. Lo que importa es el valor formal del reciclaje, el esfuerzo de asistir, las horas certificadas: la movilización. Participar en los cursillos significa respetar el código, demostrar la disposición política hacia el sistema, instituir y mantener la "fuerza productiva" lista para reincorporarse al Proyecto. Por eso, frente a la validez del título académico, al principio del mérito y la oposición pública, el cursillo emite "certificados de colaboración", que, sancionado por un gestor o institución vinculados a la red, ofrecen un capital inmediatamente empleable en el Proyecto.

3) Por último están las políticas de inserción social, cuya coordinación metropolitana ha sido firmemente exigida al Estado por la dirección político-económica del Proyecto y que funcionan con frecuencia como instrumento para combatir la llamada "espiral de silencio": desconectarse, no tener qué decir. En este sentido, los programas de garantía social, gestionados por los institutos de I+D, no tienen a menudo otra función que la de habilitar las competencias básicas del ciudadano (la más transversal: hablar), su capacidad comunicativa, con el mínimo de contenido necesario (tener de qué).

\section{Vemos así cómo el principio al que se atiene la nueva política social del Proyecto Barcelona es la actividad, la actividad en general. Se trata de "hacer algo", lo que sea, para vencer la amenaza constante y sombría de la exclusión.}

En este sentido, la justificación de un proyecto no está en el contenido sino en la forma: si conecta, vale. Como institución central de la sociedad red, los proyectos deben ser siempre neutrales, concebidos de modo que no comprometan la pura conectividad, equivalentes. Sólo esa indiferencia, esa reducción a actividad abstracta, a pura movilización, permite asimilarlos a la circulación de capital. El objetivo del Proyecto Barcelona es garantizar esa neutralidad, velar para que todo proyecto confirme y conforme su espacio social de posibilidad. Tiene que evitar que alguno, cuyo impulso deje de ser el miedo, golpee los límites del nuevo capitalismo. Que nadie rompa o se marque políticamente y bloquee el juego de la actividad abstracta. Que nadie ponga en peligro la reproducción misma del sistema. Por eso el Proyecto Barcelona necesita también de una justificación: el derecho de policía. La doctrina de la movilidad sostenible se resuelve entonces en una movilización 
sin fin, absoluta, una movilización por la movilidad misma, que reedita sui generis, como ya vimos, los vínculos estructurales entre el fascismo y la sociedad capitalista.

\section{Segundo mecanismo: EL MULTICULTURALISMO}

La carne de la ciudad empresa es la diversidad y el multiculturalismo su ideología. Una de las características más importantes del fascismo postmoderno es que la diferencia ya no le es exterior. No es aquello que queda fuera o que debe ser expulsado. Fuera sólo queda la sombra de la exclusión, de todo lo condenado a no existir. La diferencia, en cambio, se ha convertido en lo más íntimo y en lo más cercano. Como hemos visto, en la actual fase del capitalismo cada diferencia, en cuanto proyecto, debe ser movilizada y puesta a trabajar. La legitimación por la diferencia toma entonces el relevo a las disciplinas de normalización: la secuencia familia-escuela-fábrica y la identificación por la clase y la nación estallan en un abanico multicolor de identidades liberadas que cada cual debe cazar al vuelo según sus herramientas, capacidades y posibilidades de vida.

\section{Por eso el multiculturalismo es la ideología del nuevo capitalismo: cualquier estilo de vida, mientras no pretenda ser más que eso - una opción cultural entre otras - debe formar parte del capital social de la empresa que somos todos.}

Color de piel, opción sexual, gustos estéticos, colores futbolísticos, sentimiento nacional, afinidades, aficiones... todo entra a formar parte de la Barcelona multicolor, siempre que se cumplan dos condiciones: no hacer de los incipientes ghettos los agujeros negros de una amenaza y no hacer de la propia diferencia una realidad incompatible y por lo tanto subversiva. Toda diferencia está llamada a serlo mientras sea una diferencia claudicante.

Es cierto que la diversidad y multiculturalidad del archipiélago global aumentan de manera simultánea al odio xenófobo al extranjero. Pero esto no debe confundirnos. Precisamente lo que hay que entender es que el multiculturalismo no es la alternativa al racismo. Es la cara ideológica de un régimen de dominación que integra el odio al otro bajo formas y bajo circunstancias nuevas. Es el racismo de la tolerancia. Un modelo que se nos ofrece como el reverso de una moneda, la misma, que en la otra cara sólo deja espacio a los fundamentalismos. Una moneda que bajo el discurso de lo cultural distorsiona y mistifica las relaciones en las que la cultura interviene y produce sentido. En las fiestas de la diversidad y en las escuelas multiculturales aprendemos las recetas de cocina del "otro", las fechas de su calendario y los nudos de su kimono o de su "chador". Bajo tanto exotismo se cierra el espacio para las verdaderas preguntas: ¿cuándo saliste de tu casa? ¿Qué dejaste allí? ¿Qué has encontrado? ¿Cuánto ganas? ¿Estás sola? El multiculturalismo hace de la relación con el otro algo que tiene que ver con el respeto y con la curiosidad. Son las actitudes del turista que mira, huele y compra, con la tranquilidad de tener su cuenta bancaria a muchos kilómetros de distancia. Son las actitudes que nos dan la coartada para no tener que pensar qué significaría encontrarnos en la diversidad. En cada diferencia encontramos la explicación de una distancia y la justificación de una explotación.

La marca Barcelona produce diferencias y vende multiculturalismo: se propone como un modelo exitoso de gestión de la diversidad. Por eso su fiesta de presentación, el Forum Universal de las Culturas, como hemos apuntado, no es otra que la celebración de ese "Otro esterilizado". 


\section{Gestionar la diversidad}

A través de las guerras, de los movimientos migratorios y del comercio, las poblaciones, las lenguas y las culturas siempre han entrado en relación. Sólo la ficción abstracta de la identidad nacional moderna en Occidente puede hacernos pensar en el carácter estático y eterno de las identidades. Lo que ha cambiado en cada época son los términos y condiciones bajo los que se ha establecido estas relaciones. En el actual estadio de globalización de la economía, de desarrollo tecnológico y de superpoblación del planeta, podríamos decir que la diversidad ha pasado de ser un hecho puntual (a causa de una invasión, por ejemplo) o localizado (en determinados puntos comerciales) para convertirse la realidad social de cualquier metrópolis.

Las ciudades del archipiélago global son ya, inevitablemente, realidades sociales altamente diversificadas. Por eso el problema no puede plantearse en los términos de cómo integrar la diferencia, sino de cómo gestionar la diversidad. La marca Barcelona propone uno de los posibles modelos de gestión de la diversidad: la movilización de la diferencia.

Pero, ¿de qué hablamos cuando nos referimos a la diversidad, más allá del tópico folklorista? ¿En qué sentido las realidades sociales son hoy altamente diversificadas? Podríamos decir, sintetizando, que la diferencia se ha puesto en el corazón de la realidad social a partir de tres procesos:

1) La aceleración e incremento de los movimientos de población en el capitalismo global, alimentados tanto por la emigración de la mano de obra descalificada requerida por los países ricos, como por la internacionalización de las empresas y del ocio.

2) La rearticulación de la anterior sociedad disciplinaria y normalizada hacia una proliferación personalizada de opciones y de estilos de vida.

3) La difuminación de la sociedad de clases y de sus correspondientes particiones territoriales, laborales y políticas en una gradación particularizada de situaciones y de diferencias.

Por todo ello, gestionar la diversidad no significa solamente ocuparse de la inmigración proveniente de países más pobres. Significa ante todo controlar y hacer funcionar un conglomerado social habitado y compuesto por la interculturalidad (diversidad cultural), el pluralismo (diversidad de estilos y formas de vida) y el disenso (diversidad de opciones y posicionamientos).

Interculturalidad, pluralismo y disenso son los materiales de la nueva realidad social. Unos materiales que, debidamente organizados y neutralizados, articulan esta sociedad en la que toda diferencia suficientemente claudicante es movilizada y puesta a trabajar.

La marca Barcelona propone para ello un modelo concreto, dotado de dos herramientas principales: un discurso de la legitimación y una cita para el encuentro. Es lo que analizaremos en los dos puntos siguientes. 


\section{Legitimación por la diferencia}

Frente a otros modelos de gestión de la diversidad, como la ghettización (Estados Unidos), la integración (Francia) o la dualización (Japón), la marca Barcelona propone un modelo en el que la legitimación se da apelando a la diferencia misma.

Por un lado, la llamada a "ser diferente", cada uno por sí mismo y todos en el cuerpo de la ciudad, es el argumento de una justificación. Barcelona es como es porque es diferente. En Barcelona se vive como se vive, porque cada uno es diferente.

El efecto de este mecanismo de legitimación es la naturalización de las diferencias económicas, sociales y políticas: las diferencias económicas se naturalizan en la diversidad cultural; las diferencias políticas, en la diversidad de opinión y las diferencias sociales, en la diversidad de opción. Así queda neutralizado el antagonismo del que son portadoras. Cada vida, según sus atributos, tiene sus límites, sus abismos, las fronteras que no puede franquear. La ciudad, como modelo, no. Cada diferencia expresa una posibilidad más del mismo sistema. Nunca llega a ser la expresión de sus fallos, de sus contradicciones o de sus límites. El multiculturalismo es así la ideología que hace de toda forma de vida una posibilidad más, y no la posibilidad real de cuestionamiento y transformación de lo existente.

\section{Por otro lado, la diversidad misma se convierte en un valor que da valor. Lejos de ser el precio que hay que pagar para poder estar en el archipiélago global, la marca Barcelona hace de la diversidad su principal bien común.}

Que la diversidad misma sea el bien común de la ciudad implica que todo aquello que la amenace puede ser condenado. Esto instaura un nuevo régimen de valoración de lo bueno y de lo malo, o como venimos diciendo, de lo legítimo y lo ilegítimo, en el que cada diferencia se define respecto a la sombra de una amenaza. Nada en sí mismo es condenable a no ser que franquee el umbral de su propia sombra. Hay tres sombras, tres amenazas, que articulan el imaginario que pone en peligro la normalidad de lo diverso: el terrorista que habita tras la normalidad del inmigrante, el pederasta o el maltratador que se esconde tras la cotidianidad del ciudadano corriente y el violento que potencialmente puede llegar a ser toda voz crítica. La gradación que va de lo legítimo a lo ilegítimo tiene estos parámetros. Más acá de su reino de sombras no hay nada que cuestionar. El inmigrante con sus indignas condiciones de vida; el ciudadano corriente con su vida mediocre y precarizada y las voces críticas con sus quejas y protestas, teñidas a veces de colores y de buena fe... todo cabe en la ciudad multicolor. Por eso sentimos que no hay nada que denunciar, nada que cuestionar, nada que decir. Y, en cambio, está todo por hacer. Qué rabia. Cuánta rabia.

\section{Encontrarse en la diversidad}

Gestionar la diversidad también implica diseñar y promover sus formas y lugares de encuentro. El espacio público basado en las relaciones de proximidad (comunitarias, familiares, de clase, etc) ha estallado. En su lugar se propone un espacio público especializado en serlo. Un espacio público que precisamente tiene por función impedir todo encuentro fuera de sus parámetros, de sus previsiones y de su recinto.

El ejemplo salta a la vista: ¿por qué el Forum tiene que ofrecernos un espacio de encuentro cuando al inmigrante, al homosexual, al budista, a la madre 
soltera, al parado y al viejo sin más pensión que una limosna los tenemos cada día sentados a nuestro lado en el metro? ¿Por qué nos tienen que invitar a compartir nuestros olores cuando cada día en las calles de nuestra ciudad nos impregnamos de ellos?

La invitación del Forum es el símbolo y la expresión espectacularizada de lo que propone la marca Barcelona como modelo de ciudad multicultural: que converjamos en una ciudad en la que no nos podemos encontrar. Los canales de esta convergencia sin encuentro son, principalmente, tres: el intercambio (entre culturas), el equipo (en el laboral y en lo social) y el diálogo (entre opciones).

El Forum escenifica estas tres formas de relación en la diversidad. Por eso es la fiesta de una comunidad-simulacro a la que cada uno acude solo: simulacro de multiplicidad en el folklorismo; simulacro de comunicación en el diálogo entre representaciones vacías y simulacro de encuentro misma en la experiencia del gran evento. Las manos de su logo logran expresar, de nuevo, su verdad: el Forum no sólo es un laboratorio. Es la construcción de un espacio en el que juntos sigamos solos. Es la puesta en marcha de una ciudad en la que las manos tienen que seguir siendo temerosas de la cercanía de las demás. Manos que expresan su separación, su soledad. No su potencia. Quizá no son tiempos de recordar puños alzados o manos capaces de empuñar una herramienta o la propia vida... Pero qué tristes esas manos verduscas, rígidas, timoratamente cercanas.

\section{Tercer mecanismo: LA NEUTRALIZACIÓN DE LO POLÍTICO}

\section{De lo político a la política: la evacuación del conflicto}

Hemos visto que la marca Barcelona se articula tanto a través del proyecto como de la movilización de las diferencias o multiculturalismo. El efecto que producen ambos mecanismos es la neutralización de lo político, esto es, la despolitización de las relaciones sociales. Éste es el atributo que define al fascismo postmoderno, sin duda, como régimen de poder radicalmente nuevo.

De lo que se trata es de controlar el espacio de lo político pero borrándolo, clausurándolo, de tal modo que la dominación que día a día soportan nuestras vidas, su movilización total, se vuelva invisible, natural, incuestionable.

\section{Con esta evacuación del conflicto se bloquea toda referencia al antagonismo, a la resistencia provocada por la nueva forma de poder. La posibilidad de un enfrentamiento político con el sistema queda sencillamente anulada del imaginario social, relegada a un lugar de sombras -violento, terrorífico, amenazante-, al que sólo se invoca para exorcizarlo.}

La evacuación del conflicto vacía de sentido la vida, que ya solo se contempla como una línea que conduce del nacimiento a la muerte y que vamos llenando con nuestra biografía, con nuestras "historias". Es la mueca del superviviente, la resignación de la impotencia. Las dificultades para sostener una decisión común, para poner en marcha acciones colectivas capaces de sacudirse la lógica de la marca, se vuelven insuperables. El sistema fagocita todo lo que de algún modo intente cuestionarlo. Así, por ejemplo, las manifestaciones contra la guerra durante la primavera del 2003 lograron por un momento interrumpir la movilización por lo obvio y reabrir el espacio de lo político. Miles de vidas anónimas, sometidas en silencio al poder de la marca, ocuparon de pronto con toda su 
rabia, con todo su ruido de voces y cacerolas, las calles de la ciudad y sus centros comerciales... Pero su No a la guerra fue neutralizándose poco a poco en un Sí a la paz, hasta acabar convertido en un producto más de la marca Barcelona: Barcelona capital internacional de la paz.

La evacuación del conflicto encierra el mundo en una contingencia que, paradójicamente, es imposible revocar. Lo que ocurre no puede más que ocurrir y la prueba es que las cosas son como son. Basta con explicarlas para que resulten válidas, para que se vuelvan aceptables. Nada que hacer, nada que añadir. El fascismo postmoderno neutraliza a su favor, como veremos enseguida, todas las resistencias. La marca Barcelona opera sobre el ciudadano una auténtica despolitización de la existencia.

\section{La política como gestión estratégica de la marca}

En el lugar de lo político, en el hueco o vacío dejado por su ausencia, la marca Barcelona levanta a cambio el escenario de la política. La política se levanta, por tanto, no como expresión del conflicto de poder inherente a toda relación social sino como mecanismo de gobierno, como instrumento de gestión estratégica de la marca, destinado precisamente a neutralizar aquel conflicto. Destacaremos en su lógica cuatro momentos:

\section{1) La indignación moral.}

Ante todo, se trata de reducir lo político a un sentimiento subjetivo: la irritación vehemente contra todo lo que ocurre, pero descargada de la pugna que supondría su articulación en una práctica de resistencia social.

\section{El "no hay derecho", el "esto no puede ser", además de animar las tertulias y discusiones con su suministro de tópicos, permite definir el rasgo esencial del ciudadano-cliente.}

En efecto, se promueve la evaluación crítica de lo que pasa pero conectándola, a través de la indignación moral, con la desaprobación y demanda de soluciones. Se trata pues de una evaluación crítica medida por índices de satisfacción e insatisfacción. La indignación moral coloca así la política en el ámbito de las estrategias de gobierno, donde los fracasos se interpretan como errores corregibles mediante una gestión adecuada.

\section{2) La acción eficaz.}

La búsqueda de responsables es el único cuestionamiento que permite esta forma de política. Se trata de señalar al gestor que ha manejado incorrectamente el conocimiento sobre lo que ocurre, con lo que acción política y gestión administrativa quedan, como vimos al hablar del Ayuntamiento, confundidos en un solo discurso. En el fondo, y a imagen de fascismo clásico, no hay propiamente conflictos sino "problemas", disfunciones en la red social, ante las que se exige la intervención competente de nuestros "representantes".

El objetivo político, el único posible, es subsanar la disfunción mediante su diagnóstico, la evaluación de costes y el programa de intervención que pueda derivarse. 
La agenda política barcelonesa se limita, en general, a una relación de temas y procedimientos, a un cuaderno técnico de proyectos, programas y planificaciones, sin otro sentido que el de su propia ejecución. Una vez más, no hay mejor ejemplo que el Forum de las Culturas. El proyecto, el programa y la planificación estuvieron claros desde el principio. La necesidad de una gestión eficaz, de un gestor competente, también. Pero sólo a última hora y de manera confusa ha podido precisarse su finalidad política, su sentido, refiriéndolo a la necesidad de infraestructuras del barrio periférico donde se concentran las intervenciones.

\section{3) El principio de elección.}

La política se concibe como una función a cargo de expertos y profesionales, en parte elegidos, que manejan los datos e ideas que conciernen a la marca. Frente a ellos la intervención del público, esto es, la participación ciudadana, se limita a la expresión de opiniones y preferencias: ¿Le gusta lo que hacemos por su ciudad? ¿Le gusta lo que hacemos por usted?

A través de sus equipos de gestión, es decir, de los partidos políticos, la marca Barcelona confecciona sobre todo ofertas: ofertas culturales, urbanísticas, educativas; de seguridad ciudadana, de ocio y diversión, de promoción turística; ofertas para ser solidarios, para estimular el comercio, para respetar el medioambiente. Ofertas, en fin, de vida, ante las que no cabe nada más que elegir. Libremente.

El reconocimiento ante los demás depende de esa elección. El sentido de la vida, su valor como vida ciudadana, se obtiene en ese gesto radicalmente individual, solitario, definible en todo rigor como un acto de consumo.

\section{El principio de libre elección se reconvierte así en un dispositivo de individualización que neutraliza la fuerza política de la libertad.}

La imposición de ese límite ("Elige y punto") se gestiona como una demanda de ofertas por parte del propio ciudadano. A la indignación moral le corresponde ahora la figura del contrato, del intercambio mercantil, que tiñe de liberal el régimen del fascismo postmoderno. Da igual. Sujetos a su posibilismo el principio de elección nos encierra en su presente infinito, condenados a la réplica sin fin de lo que ya hay.

\section{4) El diálogo intercultural.}

La última estrategia, y acaso la fundamental, de la marca Barcelona para neutralizar lo político es reducirlo al ámbito de la cultura. Como instrumento de gestión política, la cultura se ha convertido en una instancia realmente productiva, que inunda de fetiches -símbolos, imágenes, mitos- el territorio metropolitano. Sin embargo, toda esta proliferación de signos de identidad no remite ya a un sistema de referencias compartido, capaz de una producción política común y colectiva, tan señalada en la historia de Barcelona, sino que se agota, como hemos visto, en su consumo mercantil, en su intercambio.

La marca muestra una sociedad esencialmente pacificada, exenta de conflictos. Eventualmente pueden producirse roces, incomprensiones, rivalidades propias del contacto entre culturas, pero que se reconducen a través no de la negociación sino diálogo. Mal que bien, la negociación reconoce aún el antagonismo, apunta hacia lo político. Por el contrario, el diálogo reconstruye una y otra vez el horizonte de la obviedad, de la evidencia. Basta con citar de nuevo la convocatoria a las "discusiones" del Forum: «Los diálogos son la pieza fundamental del Forum 
Universal de las Culturas. Es aquí donde conceptos de rabiosa actualidad como paz, diversidad y sostenibilidad se materializarán en unas discusiones que sin duda serán apasionantes...».

Como en el fascismo clásico -sin ir más lejos, bajo el régimen franquista- la cultura asume otra vez la función de neutralizar, de despolitizar las relaciones sociales. Y otra vez se la degrada con un tratamiento folklorista, banal y festivo, mediante el cual la ciudad se cubre de colores. En efecto, se los saca afuera. De pura vergüenza.

\section{El fascismo posmoderno y el Estado-guerra}

Hemos visto que el fascismo postmoderno anula lo político como espacio donde negociar los conflictos que suscita su nueva forma de dominación.

\section{Ahora bien, de ese modo no solo se reduce la política a estrategia de gobierno, a neutralización de las relaciones sociales, sino que se provoca una nueva politización perversa: la apertura de un espacio inédito donde lo político se expresa o ejecuta en forma de Estado-guerra.}

Así, se trata de movilizar todo el territorio decretando literalmente una guerra, esto es, un enemigo que amenaza con su terror la supervivencia -siempre frágil, vulnerable del sistema social, y contra el que todos deben mostrarse unidos. La sociedad red devuelve así en su forma más perversa, más fascista también, una dimensión -lo político- esencial a las relaciones sociales.

De entrada, el Estado-guerra confiere a la movilización general el sentido del que carecía. No se trata sólo de una movilización por la pura movilidad, de aquella movilización abstracta que analizamos al considerar el Proyecto Barcelona. Se trata también de una movilización general por la vida, en defensa de la posibilidad misma de vivir, asegurada por principio en el nuevo modo de capitalismo y amenazada, por tanto, por sus enemigos.

En segundo lugar, la instancia de la seguridad califica y distingue de modo expresamente político el nuevo vínculo social. Distinguir en el territorio al amigo del enemigo, la conexión segura de la insegura, exige del poder una anticipación que, disolviendo la opacidad, demarque de manera inequívoca la línea -irregular, sin dudadle frente, esto es, la divisoria política. Es el ataque preventivo.

Por último, el Estado-guerra tiende a construir un mundo, su mundo: el de un espacio formado ya solo por lugares vulnerables, pues todo el territorio deviene campo de batalla, objetivo del y contra el terror; el mundo, en fin, de un tiempo construido y plegado ya solo sobre las decisiones que en el curso de su avance tome el poder.

Está claro que esta nueva politización entraña enormes contradicciones. Como dijimos al principio el fascismo postmoderno no goza de la coherencia del fascismo clásico. Sin embargo es ahí, en la tensión de esas contradicciones, en su resolución siempre provisional, donde la marca Barcelona demuestra su naturaleza profunda y verdaderamente política:

a) Por un lado, si el Proyecto exige un territorio diversificado, plural, rico en diferencias, como recurso de la nueva producción, el Estado-guerra homogeneiza toda diferencia a partir de la división política elemental: amigo o enemigo.

b) De igual modo y mientras pregonan el discurso del multiculturalismo, los gestores de la marca, adscritos a una izquierda efectivamente descarada, sostienen una presión policial 
constante sobre los inmigrantes de "raza" peligrosa, simbolizada por la campaña -una auténtica cacería por las calles de Barcelona- contra los negros subsaharianos en agosto de 2002.

c) En fin, el ideario de autonomía personal, construcción del propio proyecto, etc., queda en entredicho por una llamada a la movilización que de manera expresa, esto es, bajo una coacción declarada, exige la adhesión política de todos al régimen impuesto por el Estadoguerra. 


\section{CONCLUSIÓN: NOS QUEDA LA RABIA}

Este informe no puede terminar ni con recomendaciones ni con conclusiones, como es usual en estos casos, porque no queremos reducir la complejidad. Nuestro objetivo no es dominar la realidad. Al contrario, lo que deseamos es algo completamente distinto: queremos hacer estallar esta realidad y sus códigos de acceso al mundo. ¿Cómo se combate una marca? En el mercado hay dos maneras de hacerlo: 1) Mediante la creación de otra marca que se enfrente a la primera. 2) Mediante la invención de un producto distinto que consiga dar a la marca un nuevo sentido. Ambas estrategias convergen en el mismo punto: reivindicar la marca. No es lo que queremos. Por eso defendemos desokuparla. Desokupar la marca Barcelona.

Sabemos que eso es difícil ya que la llevamos grabada sobre nuestra piel, en los estilos de vida que consumimos y en las manos que pagan el metro. Por esa misma razón no queremos conformarnos con indicaciones generales. Hemos dicho que una marca es una determinada organización de sentido, de relaciones de poder y de explotación. Y usualmente añadiríamos: se trata de cortocircuitar dichas relaciones. Pero ¿cómo hacerlo? ¿Inventamos frases ingeniosas contra el sentido común? ¿Intentamos hacer frente a un Estado penal cada vez más dominante? ¿Denunciamos las condiciones de trabajo hoy existentes?

Todo esto es necesario. Pero también hay que apuntar más allá. Como hemos mostrado la marca Barcelona se aguanta en parte sobre la pasividad, pero aún más sobre nuestro propio vivir. Es con nuestra vida como se construye dicha marca. Por eso tenemos que dañar las seguridades y certezas en las que nos apoyamos. Después tenemos que dañar nuestro cuerpo para que no funcione reproduciendo esta realidad. Hay que resistirse a la movilización total del fascismo postmoderno y abrir bloques de espacio-tiempo donde habitar. Aunque sepamos perfectamente que fuera de la marca Barcelona sólo existe el vacío... Hay que dejar entrar el vacío dentro de nosotros. Para coger fuerza.

No nos une una experiencia común del trabajo, ni siquiera la de sufrir una misma precariedad. La precariedad es un efecto y una construcción capitalista que nos hace ser lo que somos. Pero no nos une lo que somos sino lo que nos lleva más allá de lo que somos. Nos une nuestro querer vivir, que es mío y tuyo, que es común.

\footnotetext{
Nos queda la rabia. Desokupar la marca Barcelona es iniciar una política nocturna, construida desde las resistencias que no necesitan esperar un mañana. Pero también es iniciar una política diurna hecha a partir de una estrategia de objetivos: derecho de ciudadanía para todos y renta básica universal.
}

La marca Barcelona pretende ser un refugio en el mar de horror de la globalización armada. Como hemos mostrado en este informe, no es verdad. El modelo social de la marca Barcelona, con su movilización total de la vida como proyecto de una diversidad despolitizada, es un laboratorio del fascismo postmoderno. Frente a eso, nos queda la rabia. Rabia contra el mundo por ser como es. Rabia contra nosotros mismos, porque cada noche dormimos tranquilamente en vez de estar despiertos acechando.

Acechando... 


\section{ANEXO}

\section{Barcelona, anécdotas de una marca}

En BCN dicen que hace exactamente 100 años la habitaban $\mathbf{5 5 6 . 7 8 7}$ personas y $\mathbf{1 . 5 8 2 . 7 3 8}$ vivimos en ella ahora, 834.589 mujeres, 748.149 hombres, 32.946 ecuatorian@s, 13.594 magrebies, 13.307 colombian@s, 13.163 peruan@s, 11.427 argentin@s, 10.198 pakistanies,9.619 italian@s, 7.195 chin@s,6.777 dominican@s,6.577 frances@s, 5.871 filipin@s,4.810 bolivian@s,4.465 chilen@s,4.170 alemanes, 3.971 mejican@s, 3.557 brasileñ@s, 3.451 ingleses, 3.084 ruman@s, 2.829 venezolan@s, 2.801 uruguay@s, 2.792 indi@s, 2.570 rus@s, 2.364 estadounidenses, 2.325 ucranian@s, 2.301 cuban@s, 1.702 argelin@s, 1.629 portugueses, 1.437 japoneses, 1.290 búlgar@s, 1.056 armeni@s, 863 hondureñ@s, 805 belg@s, 795 georgian@s, 768 nicaragüenses, 718 polac@s, 677 guinean@s, 625 salvadoreñ@s y sombras, muchas sombras. Nacen cada año en Barcelona casi 13.000 bebes, más niños que niñas y más en Octubre, Julio y Enero, acostumbran a llamarse Marc y María. Se inhuman en nuestra ciudad 13.897 cadáveres y se incineran 6.532, mueren anualmente más mujeres que hombres y las mayores defunciones se registran en Enero, Diciembre y Junio. La edad media de nuestra ciudadanía ronda los 43 años, se casan anualmente casi $\mathbf{6 . 0 0 0}$ parejas, se divorcian 2.300 , se separan 3.000 y se realizan en nuestros hospitales más de $\mathbf{5 . 0 0 0}$ abortos legales - en ellos - con apenas $\mathbf{5 . 0 0 0}$ camas públicas se atienden más de $\mathbf{7 1 1 . 0 0 0}$ urgencias médicas y el 061 recibe $\mathbf{6 3 1 . 1 4 2}$ llamadas. Nuestros 9 cementerios nos esperan con $\mathbf{2 . 4 1 2 . 5 6 0 ~ m 2 ~ d e ~ t i e r r a ~ d e s t i n a d a ~ a ~}$ nuestros marchitos cuerpos. A nuestras mujeres les esperan 82 años de aburrida vida y a nuestros hombres 75. Anualmente las más de $\mathbf{2 . 0 0 0}$ oficinas bancarias ubicadas en nuestra ciudad realizan más de $\mathbf{1 0 0 . 0 0 0}$ operaciones hipotecarias cuyo importe supera los $\mathbf{1 1 . 0 0 0}$ millones de Euros y los tardamos en pagar una media de 20 años. En Barcelona tenemos más de $\mathbf{3 8 . 0 0 0}$ máquinas tragaperras, y en juegos y loterías, nos jugamos al año más de 2.000 millones de euros. Cada uno de nosotros consumimos en nuestros hogares casi $\mathbf{5 0 ~ \mathrm { m } _ { 3 }}$ de agua potable, $1.729 \mathrm{Kw}$. de electricidad y más de 1.300 Termias de gas ciudad. Por nuestro mercado central pasan anualmente más de 27 millones de flores, 24.000 toneladas de carne, $\mathbf{8 7 . 0 0 0}$ toneladas de pescado y marisco, $\mathbf{5 0 0 . 0 0 0}$ toneladas de verduras $y$ hortalizas, más de $\mathbf{4 0 0 . 0 0 0}$ toneladas de frutas. Por nuestro puerto marítimo pasan 1.690.524 pasajeros, 576.648 cruceristas, se mueven $\mathbf{3 2 . 6 0 8 . 1 9 5}$ toneladas de mercancías varias. Transitan por nuestras aguas casi 9.000 buques, 1.700 ferrys y 600 cruceros turísticos visitan nuestras costas. Dicen que 21.168.997 pasajeros pasan por nuestro aeropuerto y $\mathbf{7 5 . 2 1 4}$ toneladas de cosas llegan desde el aire. En Barcelona hay más de 100 líneas de autobuses y más de 1.000 buses que paran en 2.365 paradas y recorren anualmente más de $43.254 \mathrm{Km}$. el metro tiene más de 100 estaciones y sobrepasa los 100 $\mathrm{Km}$. de túneles recorriendo al año $60.978 \mathrm{Km}$. En nuestras calles hay más de $100 \mathrm{Km}$. de carril para bicicletas y $\mathbf{3 0 . 0 0 0}$ ciclistas pedalean cada día. En Barcelona hay $\mathbf{9 3 6 . 4 6 4}$ vehículos, 611.807 turismos, 141.283 motos, 42.585 furgonetas, 34.321 camiones, 1.776 autocares. En la ciudad del Forum habian censados hace poco 1.285.620 electores, de los cuales votaban $\mathbf{7 5 8 . 1 5 9}$ y con tan sólo $\mathbf{2 5 3 . 4 6 2}$ se obtiene el poder político de la ciudad. En Barcelona hay más de $\mathbf{2 0 0 . 0 0 0}$ negocios incluyendo los comercios, 183.920 actividades empresariales anuales, más de $\mathbf{2 . 3 5 0}$ empresas de capital extranjero, se realizan más de $\mathbf{6 5}$ 
ferias oficiales, $\mathbf{1} .380$ congresos o convenciones, y vienen 23.758 expositores. En nuestra ciudad nuestras oficinas de correos mueven anualmente más de 650.000 .000 de papeles, cartas y paquetes. En Barcelona despiertan cada día $\mathbf{2 0 0 . 0 0 0 ~ e s c o l a r e s ~ y ~ c a s i ~ n o ~ d u e r m e n ~}$ 18.000 profesores, hay casi $\mathbf{2 0 0 . 0 0 0 ~ u n i v e r s i t a r i o s ~ q u e ~ e s t u d i a n ~ m a ́ s ~ d e ~} \mathbf{2 5 0}$ licenciaturas en nuestras 11 universidades, de ellos 7.000 son extranjeros y algunos también asisten a nuestras 24 escuelas internacionales. En Barcelona hay más de 30 bibliotecas, 13 espacios públicos, miles de privados, más de 105 exposiciones, 20 conciertos multitudinarios y la ciudad guarda en sus estantes oficiales casi $\mathbf{8 . 0 0 0 . 0 0 0 ~ v o l u ́ m e n e s ~ i m p r e s o s ~ d e ~ l o s ~ c u a l e s ~ s e ~}$ prestan 2.000.000 de ejemplares. En Barcelona sale el sol 2.777 horas cada 365 días y durante $\mathbf{8 3}$ la lluvia empapa a sus $\mathbf{8 3 . 0 0 0}$ edificios de los cuales son vivenciales alrededor de 70.000, de estos se convierten en viviendas un poco más de 600.000 y la mitad no llegan a 70 m2. En Barcelona tenemos $\mathbf{3 8 8 . 8 4 4}$ árboles de éstos 157.022 son Platanus hibridae, un Zoo con 426 especies diferentes, 4.472 calles, 46 teatros que realizan más de $\mathbf{5 7 5}$ espectáculos, 170 cines, 82 consulados, 10 rascacielos, 100 aparcamientos subterráneos, 11.007 Km2 de calzadas sin contar ni rondas ni túneles, $5.985 .349 \mathrm{~m}_{2}$ de aceras, $1.500 \mathrm{Km}$. de redes de alcantarillado, 886 monumentos públicos y de éstos 5 son patrimonio de la humanidad. En Barcelona hay 478 esculturas , 49 monolitos, 71 plazas conmemorativas, más de 1.100 espacios deportivos públicos, 4.240 metros de playa, 71 piscinas, 112 galerías de arte, 400 librerías especializadas, 59 parques urbanos, 762 floristerías, casi 4.000 peluquerías, 336 agencias de viaje, 409 quioscos, 10.500 taxis negros y amarillos que descansan en 192 paradas, 1.540 fuentes públicas, más de 26.000 contenedores. En Barcelona anualmente se producen 1.275.907 infracciones, 126.408 delitos, 20.107 robos, más de 138.000 coches retira la grúa de nuestras calzadas, 27.442 borracheras oficiales, casi 5.000 incendios o explosiones, se rompen 4.066 semáforos de los casi $\mathbf{3 0 . 0 0 0}$ existentes, se roban o se destruyen 2.000 señales, se encienden cada día 107.084 farolas, $y$ 2.000 personas con 1.000 vehículos intentan limpiarla. En Barcelona hay 19.669 papeleras, 1.666 buzones, 29.344 bancos públicos, 1.607 cabinas, 3.310 teléfonos callejeros, 3.963 jardineras, 576 áreas de juegos infantiles. En Barcelona cada día abren casi 7.100 bares o cafés y más de 2.300 restaurantes, 200 hoteles con casi 17.000 habitaciones, 423 establecimientos donde pernoctan $\mathbf{8 . 7 0 0 . 0 0 0}$ individuos de los cuales $\mathbf{3 . 5 0 0 . 0 0 0}$ son turistas y se quedan entre nosotros una media de 2,5 días al año. En Barcelona cada uno de nosotros se despoja diariamente de 1,53 Kg. de basura, 8,7 Kg. De vidrio, 15,36 Kg. de papel, 3,4 Kg. de envases y 12,25 Kg. de muebles. Se editan 16 revistas semanales, 6 quincenales, 114 mensuales, 35 bimestrales, 18 trimestrales, diariamente salen al mercado 48 libros en castellano y 15 en catalán, abren 9 periódicos, suenan 32 radios autóctonas 24 horas y 11 televisiones territoriales nos bombardean con imágenes irracionales. En Barcelona los perros tiene 142 sanitarios públicos repartidos por la ciudad y los ciudadan@s tenemos 5 ... y todo esto ocurre en una superficie de apenas $101 \mathrm{Km} 2$, aquí, en BCN ... 